\title{
Perancangan Sistem Informasi Pelayanan Puskesmas Wates Kabupaten Pringsewu Berbasis Android
}

\author{
Andreas Andoyo ${ }^{\text {1), Jimi Ali Baba }}{ }^{2)}$, Maghrifa ${ }^{3)}$, Dita Novita Sari ${ }^{4)}$ \\ 1)23)4) Prodi Sistem Informasi, STMIK Pringsewu, Lampung \\ Jl. Wisma Rini No. 09 Pringsewu, Lampung, Indonesia \\ 1) aandoyo@gmail.com, ${ }^{2)}$ jimialibaba@gmail.com, ${ }^{3)}$ rifaongol7@gmail.com, \\ 4)ditanovitasari@gmail.com
}

\begin{abstract}
The application of information technology in the health sector is believed to be able to provide various benefits for health service providers. With the support of this technology, the benefits that can be obtained include the availability of accurate and comprehensive patient health information, so that providers can provide a variety of the best possible care. Furthermore, the application of complete and accurate information technology can help in the diagnosis process, minimize medical errors and can offer safe health services at a low cost. The purpose of this study is to produce a patient registration service information system, can contact contacts on picket scheduling. The research method used is the method of data collection and interview methods. While the system design method used is the SDLC (System Development Life Cycle) method, which is the waterfall method. The research was carried out at the Wates Community Health Center. This application can facilitate the registration of patients online and contact the contact at the Puskesmas picket scheduling.
\end{abstract}

Keywords-Information System, Android, MySQL, Puskesmas

Intisari- Penerapan teknologi informasi di bidang kesehatan ini diyakini dapat memberikan berbagai manfaat bagi provider pelayanan kesehatan. Dengan dukungan teknologi tersebut, manfaat yang dapat diperoleh diantaranya adalah tersedianya informasi kesehatan pasien yang akurat dan komprehensif, sehingga provider dapat memberikan berbagai kemungkinan perawatan terbaik. Lebih lanjut dengan penerapan teknologi informasi yang lengkap dan akurat dapat membantu dalam proses diagnosa, meminimalkan medical error serta dapat menawarkan pelayanan kesehatan yang aman dengan biaya rendah. Tujuan dari penelitian ini adalah Menghasilkan sistem informasi pelayanan pendaftaran pasien, dapat menghubungi kontak pada penjadwalan piket. Metode penelitian yang digunakan adalah metode pengumpulan data dan metode wawancara. Sedangkan metode perancangan sistem yang digunakan adalah metode SDLC (System Development Life Cycle) yaitu metode waterfall. Pelaksanaan penelitian dilakukan di Puskesmas Wates. Aplikasi ini dapat mempermudah dalam pendaftaran pasien secara online dan menghubungi kontak pada penjadwalan piket puskesmas.

Kata Kunci- Sistem Informasi, Android, MySQL, Puskesmas

\section{PENDAHULUAN}

\section{A. Latar Belakang Masalah}

Penerapan teknologi informasi di bidang kesehatan ini diyakini dapat memberikan berbagai manfaat bagi provider pelayanan kesehatan. Dengan dukungan teknologi tersebut, manfaat yang dapat diperoleh diantaranya adalah tersedianya informasi kesehatan pasien yang akurat dan komprehensif, sehingga provider dapat memberikan berbagai kemungkinan perawatan terbaik. Lebih lanjut dengan penerapan teknologi informasi yang lengkap dan akurat dapat membantu dalam proses diagnosa, meminimalkan medical error serta dapat menawarkan pelayanan kesehatan yang aman dengan biaya rendah [1].

Menurut Dian, staff pengolahan data dan informasi Puskemas di Desa Wates KM.36 Kecamatan Gadingrejo Kabupaten Pringsewu Pelayanan kesehatan masyarakat, pelayanan masih menggunakan manual atau belum menggunakan sistem berbasis android. Berdasarkan penelitian dilakukan oleh Aslam Fatkhudin [2] sistem informasi pendaftaran pada klinik dr. Veri Berbasis Android ini telah berhasil dibuat dengan menggunakan framework lonic dan AngularJS sebagai front-end, PHP sebagai backend, dan MySQL sebagai database. Dalam aplikasi ini, user dapat mendaftarkan beberapa pasien dalam satu akun [2]. Berdasarkan penelitian dilakukan oleh Dedy Setiawan [3] perancangan sistem informasi rekam medic bertujuan dalam rangka meyiapkan serta meningkatkan pelayanan pasien. Metode perangcangan sistem yang peneliti gunakan adalah Metode Waterfall. Metode Waterfall memiliki beberapa tahapan yaitu Analisis, Perancangan Sistem, Implementasi, 
Integrasi, Operasi dan Pemeliharaan. Dalam proses pengumpulan data penelitian menggunakan metode observasi, wawancara, dan studi pustaka [3]. Berdasarkan penelitian dilakukan oleh Jenie Sundari [4] perancangan $e$ service pada puskesmas yang di ajukan memberi suatu alternatif pemecahan masalah dalam sistem registrasi dan pengambilan nomor untuk pasien. Dengan dibuatnya web ini, pasien dapat dengan mudah melihat informasi mengenai jadwal dokter yang ada serta informasi terkait puskesmas.

Dilihat dari penelitian-penelitian diatas peneliti tersebut menggunakan framework lonic dan AngularJS sebagai front-end, PHP sebagai back-end, dan MySQL sebagai database untuk membuat sistem pendaftaran berbasis android. Dibandingkan dengan penelitian yang dilakukan, peneliti tidak menggunakan framework lonic dan AngularJS sebagai front-end, melainkan menggunakan bahasa pemrograman java untuk penyajian database menggunakan MySQL dan metode penelitian yang digunakan adalah metode pengumpulan data dan metode wawancara. Sedangkan metode perancangan sistem yang digunakan adalah metode SDLC (System Development Life Cycle) yaitu metode waterfall.

Puskesmas wates dalam melakukan pelayanan seperti pendaftaran pasien, pengambilan nomor antrian, pembuatan surat sakit, dan ingin mengetahui informasi harus datang langsung ke puskesmas tersebut. Kendala untuk pasien yaitu ketika sudah datang harus mengantri terlebih dahulu untuk melakukan pendaftaran. Dengan adanya pembuatan perancangan sistem infornasi pelayanan puskesmas berbasis android agar dapat mempermudah melayani bagi masyarakat dan tidak harus mengunjungi langsung ke puskesmas untuk mendaftar, menghubungi kontak pada penjadwalan piket tersebut.

Berdasarkan uraian diatas meyakinkan penulis untuk membangun sebuah perancangan sistem informasi pelayanan puskesmas berbasis android, agar masyarakat bisa mengetahui informasi tentang puskesmas tersebut, mempermudah masyarakat untuk melakukan pendaftaran, dan menghubungi kontak pada penjadwalan piket.

\section{B. Rumusan Masalah}

Dari latar belakang diatas permasalahan yang akan dihadapi adalah:

1) Bagimana membangun sebuah sistem informasi yang mampu menyampaikan informasi tentang puskesmas di desa Wates.

2) Bagaimana merancang sebuah sistem aplikasi pendaftaran pelayanan puskemas di desa Wates secara online.

3) Bagaimana merancang sebuah sistem aplikasi berbagai pelayanan puskemas dan dapat menghubungi kontak yang ada pada penjadwalan piket.

\section{Tujuan dan Manfaat Penelitian}

Adapun tujuan yang dilakukan penelitian adalah:

1) Untuk menentukan sistem yang sedang berjalan, membuat desain sistem, analisis dan pengujian sistem.
2) Untuk mengimplementasikan pelayanan dan informasi puskesmas di Desa Wates berbasis android.

3) Menghasilkan sistem informasi pelayanan pendaftaran pasien, dapat menghubungi kontak pada penjadwalan piket.

Adapun manfaat yang dilakukan penelitian adalah:

1) Adanya sistem informasi puskesmas berbasis android untuk mempermudah mengetahui informasi tentang puskesmas tersebut.

2) Mempermudah dalam melakukan pelayanan seperti pendaftaran pasien, menghubungi kontak pada penjadwalan piket.

\section{TINJAUAN PUSTAKA}

\section{A. Konsep Sistem Informasi}

Sistem informasi dapat didefinisikan sebagai kombinasi teratur dari orang-orang, hardware, software, jaringan komunikasi dan sumber daya data yang mengumpulkan, mengubah, dan menyebarkan informasi dalam sebuah organisasi [5][6].

Fungsi dari sistem informasi yaitu untuk meningkatkan aksesiblitas data yang ada secara efektif dan efisien kepada pengguna, tanpa dengan prantara sistem informasi, memperbaiki produktivitas aplikasi pengembangan dan pemeliharaan sistem, menjamin tersedianya kualitas dan keterampilan dalam memanfaatkan sistem informasi secara kritis, mengidentifikasi kebutuhan mengenai keterampilan pendukung sistem informasi, dan mengembangkan proses perencanaan yang efektif [7].

Adapun komponen-komponen dari sistem informasi adalah sebagai berikut [8]:

1) Komponen input, data yang masuk ke dalam sistem informasi.

2) Komponen model, kombinasi prosedur, logika dan model matematika yang memproses data yang tersimpan di basis data dengan cara yang sudah ditentukan untuk menghasilkan keluaran yang diinginkan.

3) Komponen output, hasil inforrmasi yang berkualitas dan dokumentasi yang berguna untuk semua tingkatan manajemen.

4) Komponen teknologi, alat dalam sistem informasi, teknologi digunakan dalam menerima input, menjalankan model, menyimpan dan mengakses data, menghasilkan dan mengirimkan output dan memantau pengendalian sistem.

5) Komponen basis data, kumpulan data yang saling berhubungan yang tersimpan di dalam computer dengan menggunakan software database.

6) Komponen control, komponen yang mengendalikan ganguan terhadap sistem informasi.

\section{B. Puskesmas (Pusat Kesehatan Masyarakat)}

Pusat Kesehatan Masyarakat (Puskesmas) adalah suatu kesatuan organisasi kesehatan fungsional yang merupakan pusat pengembangan kesehatan masyarakat dan membina peran serta masyarakat, disamping memberikan pelayanan 
menyeluruh dan tepadu kepada masyarakat di wilayah kerjanya dalam bentuk kegiatan pokok. Puskesmas merupakan salah satu tempat yang didalamnya terjadi proses pertukaran informasi dengan kolaborasi, mobilitas, dan integrasi data, baik di dalam Puskesmas itu sendiri atau dalam hubungan keluar dengab Dinas Kesehatan yang membawahinya [9].

\section{Android}

Android merupakan sistem operasi yang berbasis linux yang bersifat open source dan dirancang untuk perangkat layar sentuh seperti smartphone dan komputertablet. Android mencakup keseluruhan sebuah aplikasi, mulai dari sistem operasi sampai pengembangan aplikasi itu sendiri. Pengembangan aplikasi pada platform android menggunakan dasar bahasa pemrograman Java. Platfrom pengembangan aplikasi android bersifat open-source atau terbuka, sehingga dapat mengembangkan kemampuan untuk membangun aplikasi yang inovatif [10][11][12] .

\section{JAVA}

Java merupakan sebuah bahasa pemrograman berorientasi objek yang dapat berjalan pada platform yang berbeda, baik di Windows, Linux, serta sisem operasi lainnya. Dengan menggunakan java, kita dapat mengembangkan banyak aplikasi yang dapat digunakan pada lingkungan yang berbeda, seperti: desktop, mobile, internet, dan lain-lain. Struktur program java terdiri atas mengimpor paket (import package) dan class yang dibuat oleh user dan class utama (main)[13].

\section{E. MySQL (My Structured Query Language)}

Menurut Abdul Kadir (2008), MySQL adalah salah satu jenis database server yang sangat terkenal. Kepopulerannya disebabkan MySQL menggunakan SQL sebagai bahasa dasar untuk mengakses databasenya. Selain itu, ia bersifat open source. MySQL ini juga memiliki kelebihan dalam penggunaannya di database yaitu memiliki lisensi GPL dan juga Multiplatform, bisa diintegrasikan menggunakan beberapa bahasa pemrograman misalnya Java, Net, Perl dan Python, adapun kekurangan yang perlu anda ketahui yang diantaranya adalah kurang mendukung bahasa pemrograman visual/Desktop atau juga Visual Basic sehingga aplikasi visual jarang digunakan [14][15].

\section{F. Sistem Informasi Kesehatan Terintegrasi}

Menurut Etty Ernawati [16], yang dimaksud sistem informasi kesehatan terintegrasi adalah mewujudkan dan mengembangkan Local area Network yang menggabungkan sarana kesehatan milik pemerintah dan swasta sebagai komponen sistem yang ada di Indonesia dan akan memanfaatkan website dan access point lain agar data kesehatan dan kedokteran dapat dimanfaatkan secara luas dan bertanggung jawab dan dalam rangka memperbaiki pelayanan kesehatan sehingga kepuasan pengguna dapat dicapai sebaik-baiknya serta ddigunakan dalam pertukaran informasi pada pelayanan kesehatan [16].

\section{METODOLOGI}

\section{A. Metode Pengumpulan Data}

Metode pengumpulan data berupa suatu pernyataan (statement) tentang sifat, keadaan, kegiatan tertentu dan sejenisnya. Pengumpulan data dilakukan untuk memperoleh informasi yang dibutuhkan dalam rangka mencapai tujuan penelitianMetode pengumpulan data berupa suatu pernyataan tentang sifat, keadaan, kegiatan tertentu dan sejenisnya. Dalam hal ini peneliti mengambil objek penelitian pada Pukesmas Pekon Wates. Metode pengumpulan data pada penelitian ini menggunakan 3 cara berikut merupakan uraian yang digunakan:

\section{1) Observasi}

Suatu metode pengumpulan data yang dilakukan dengan mengamati langsung, melihat dan mengambil suatu data yang dibutuhkan di tempat penelitian itu dilakukan. Observasi juga bisa diartikan sebagai proses yang kompleks. Pengumpulan data yang dilakukan di Puskesmas Pekon Wates.

\section{2) Wawacara}

Wawancara merupakan salah satu teknik pengumpulan data yang dilakukan melalui tatap muka langsung dengan narasumber dengan cara tanya jawab langsung. Wawancara dilakukan dengan staff IT Puskesmas Pekon Wates.

\section{3) Angket}

Teknik pengumpulan informasi yang memungkinkan analis mempelajari sikap-sikap, perilaku serta karakteristik di beberapa pengguna system.

\section{B. Metode Pengembangan Sistem}

Metode pengembangan sistem pada sistem pembuatan aplikasi pelayanan puskemas berbasis android dalam penelitian ini adalah model Waterfall. Pressman [17] menjelaskan bahwa : Metode air terjun atau yang sering disebut metode waterfall sering dinamakan siklus hidup klasik (classic life cycle), dimana hal ini menggambarkan pendekatan yang sistematis dan juga berurutan pada pengembangan perangkat lunak, dimulai dengan spesifikasi kebutuhan pengguna lalu berlanjut melalui tahapan-tahapan perencanaan (planning), permodelan (modeling), konstruksi (construction), serta penyerahan sistem ke para pelanggan/pengguna (deployment), yang diakhiri dengan dukungan pada perangkat lunak lengkap yang dihasilkan [17].

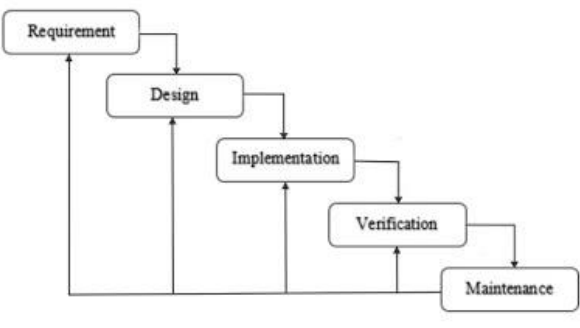

Sumber: Pressman [17]

Gambar 1. Model Waterfall 
Dalam pengembangan metode waterfall memiliki beberapa tahapan yang berurut yaitu: requirement (analisis kebutuhan), design system (desain sistem), Coding (pengkodean) \& Testing (pengujian), Penerapan Program, pemeliharaan.

\section{1) Requirement Analisis}

Tahap ini pengembang sistem diperlukan komunikasi yang bertujuan untuk memahami perangkat lunak yang diharapkan oleh pengguna dan batasan perangkat lunak tersebut. Informasi ini biasanya dapat diperoleh melalui wawancara, diskusi atau survei langsung. Informasi dianalisis untuk mendapatkan data yang dibutuhkan oleh pengguna.

\section{2) System Design}

Spesifikasi kebutuhan dari tahap sebelumnya akan dipelajari dalam fase ini dan desain sistem disiapkan. Desain Sistem membantu dalam menentukan perangkat keras (hardware) dan sistem persyaratan dan juga membantu dalam mendefinisikan arsitektur sistem secara keseluruhan.

\section{3) Implementation}

Pada tahap ini, sistem pertama kali dikembangkan di program kecil yang disebut unit, yang terintegrasi dalam tahap selanjutnya. Setiap unit dikembangkan dan diuji untuk fungsionalitas yang disebut sebagai unit testing.

\section{4) Integration \& Testing}

Seluruh unit yang dikembangkan dalam tahap implementasi diintegrasikan ke dalam sistem setelah pengujian yang dilakukan masing-masing unit. Setelah integrasi seluruh sistem diuji untuk mengecek setiap kegagalan maupun kesalahan.

\section{5) Operation \& Maintenance}

Tahap akhir dalam model waterfall. Perangkat lunak yang sudah jadi dijalankan serta dilakukan pemeliharaan. Pemeliharaan termasuk dalam memperbaiki kesalahan yang tidak ditemukan pada langkah sebelumnya. Perbaikan implementasi unit sistem dan peningkatan jasa sistem sebagai kebutuhan baru.

\section{Kerangka Fikir Penelitian}

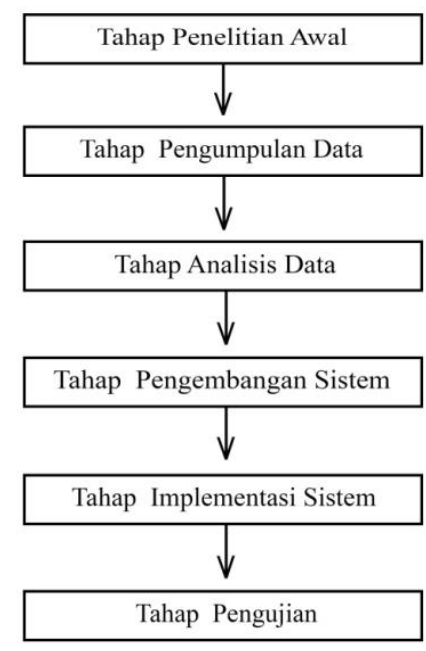

Gambar 2. Kerangka Pikir Penelitian
Adapun uraian dari kerangka pikir penelitian diatas sebagai berikut:

\section{1) Tahap Penelitian Awal}

Tahap ini merupakan tahap awal dalam pembuatan penelitian ini. Yang terdiri dari menetukan topik penelitian, mengidentifikasi masalah, dan mencari referensi.

\section{2) Tahap Pengumpulan Data}

Tahap ini menggunkan metode observasi, wawancara, dan angket.

\section{3) Tahap Analisis Data}

Setelah pengumpulan data diatas selesai selanjutnya dilakukan analisis terhadap data. Hal ini bertujuan untuk melakukan pengelompokan terhadap data tersebut sehingga akan memudahkan penulis di dalam melakukan analisis berikutnya.

\section{4) Tahap Pengembangan Sistem}

Tahap ini membahas tentang perancangan dan pengembangan dari model sistem dengan menentukan rancangan input dalam membangun suatu aplikasi pelayanan puskesmas berbasis android dengan metode waterfall.

\section{5) Tahap Implementasi Sistem}

Tahapan berikutnya yang akan dilakukan di dalam penelitian adalah melakukan implementasi dari sistem yang telah dirancang.

\section{6) Tahap Pengujian}

Pada tahap akan dilakukan pengujian pada sistem yang telah dibangun menggunakan sistem testing menggunakan pengujian Alpha dan Beta, sehingga kesalahan dari sistem dapat diminimalisasi atau bahkan dihilangkan. Pengujian sistem ini dilakukan untuk mendapatkan hasil yang akurat.

\section{HASIL PEMBAHASAN}

\section{A. Desain Sistem}

Desain sistem adalah menentukkan bagaimana suatu sistem akan menyelesaikan apa yang mesti diselesaikan, tahap ini menyangkut mengkonfigurasi dari komponen komponen perangkat lunak dan perangkat keras dari suatu sistem sehingga setelah instalasi sistem akan benar-benar memuasakan rancang bangun yang telah ditetapkan paad akhir tahap analisis sistem. Dalam membangun perancangan sistem informasi pelayanan puskesmas wates difokuskan menggunakan rancangan flowchart.

\section{1) Flowhart}

Flowchart merupakan gambaran dari urutan dari sistem informasi pelayanan puskesmas di Wates.

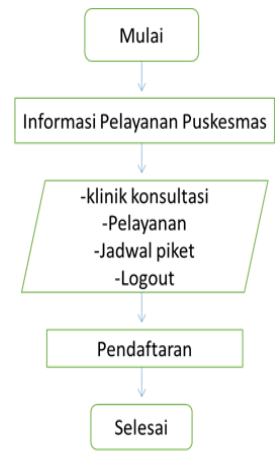

Gambar 3. Flowchart sistem informasi pelayanan puskesmas 
2) Flowchart pendaftaran pasien

Flowchart ini menggambarkan urutan dari system pendaftaran pasien puskesmas wates.

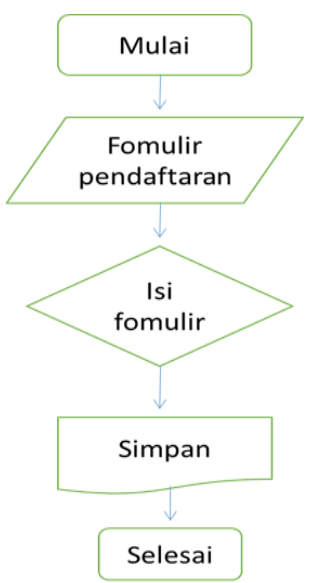

Gambar 4. Flowchart pendaftaran pasien

\section{B. Desain Antarmuka}

Desain antarmuka merupakan tampilan dimana pengguna berinteraksi dengan sistem. Berikut ini adalah tampilan halaman home pada aplikasi pelayanan puskesmas wates.

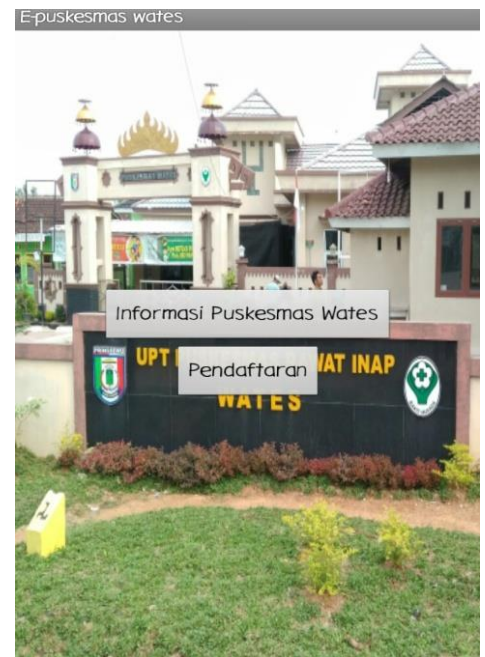

Gambar 5. Tampilan Home aplikasi pelayanan puskesmas wates

\section{Implementasi}

\section{1) Implementasi Aplikasi}

Dalam perancangan sistem informasi pelayanan puskesmas berbasis android, penulis merancang sebuah aplikasi yang tujuannya untuk mempermudah dalam mendaftar pasien, melihat informasi puskemas tersebut.

2) Implementasi halaman home

Halaman home merupakan halaman yang pertama kali dilihat klien/pengunjung saat mengakses sistem android.

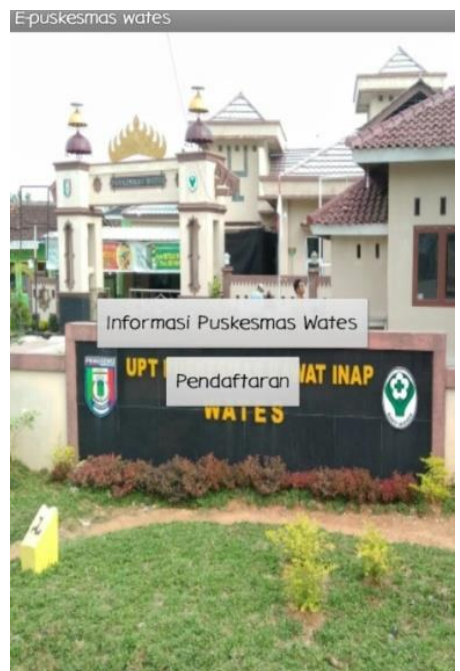

Gambar 6. Tampilan home aplikasi pelayanan puskesmas wates

3) Implementasi halaman pelayanan

Halaman pelayanan ini merupakan informasi berbagai pelayanan puskesmas wates, agar pasien dapat mengetahui berbagai pelayanan di puskesmas wates.

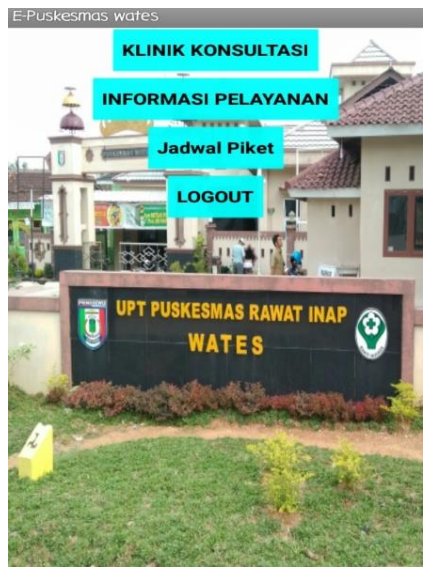

Gambar 7. Tampilan informasi pelayanan puskesmas wates

\section{4) Implementasi fomulir pendaftaran}

Implementasi fomulir pendaftaran ini mempermudah untuk mendaftar pasien secara online.

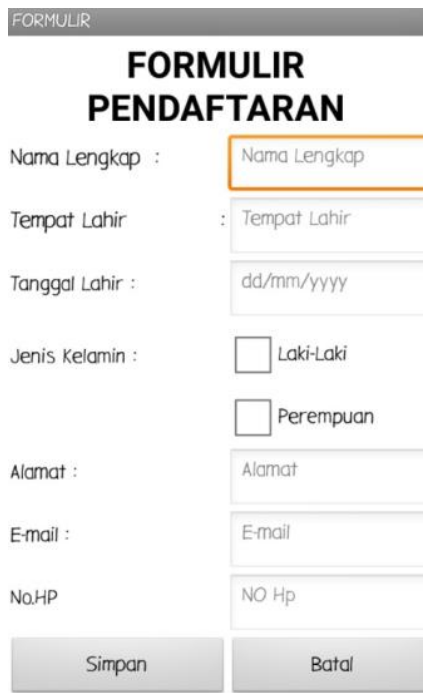

Gambar 8. Tampilan fomulir pendaftaran pasien puskesmas wates 


\section{Analisa Penelitian}

Analisa hasil penelitian merupakan hasil dari kuesioner yang telah diberikan kepada responden. Dalam kuesioner yang dilakukan penulis mendapatkan hasil tentang bagaimana tampilan awal dan fungsi aplikasi E-puskesmas. Responden rata-rata memberikan jawaban bahwa tampilan dalam aplikasi E-puskesmas cukup menarik dan mudah dipahami oleh pengguna jasa yang masih awam akan teknologi.

\section{KESIMPULAN}

\section{A. Kesimpulan}

Setelah terciptanya sistem informasi berbasis android pada puskesmas Wates Kecamatan Gadingrejo, maka penulis dapat menyimpulkan bahwa berbagai permasalahan mengenai terbatasnya informasi dapat disimpulkan sebagai berikut:

1) Bagimana membangun sebuah sistem informasi yang mampu menyampaikan informasi tentang puskesmas di desa Wates.

2) Dengan merancang sebuah sistem aplikasi pendaftaran pelayanan puskemas di desa Wates secara online.

3) Dengan merancang sebuah sistem. aplikasi berbagai pelayanan puskemas dan dapat menghubungi kontak yang ada pada penjadwalan piket.

\section{B. Saran}

Dari hasil penelitian yang dilakukan masih banyak kekurangan pada aplikasi E-puskesmas untuk databasenya belum bisa berjalan, disarankan bagi penelitian yang akan datang dapat menggunakan database MySQL dan bisa berjalan secara otomatis.

\section{REFERENSI}

[1] Divisi Mutu PKMK FK UGM, "Penerapan Teknologi Informasi dalam Peningkatan Mutu Pelayanan Kesehatan,"2017. [Online]. Avaible: https://www.mutupelayanankesehatan.net.

[Accessed: 21-Apr-2019].

[2] A. Fatkhudin dan D. N. Alifiani, "Sistem Informasi Pendaftaran Pasien Pada Klinik dr. Veri Kajen Kabupaten Pekalongan Berbasis Android," J. Ilm. Edutic, vol. 4, no. 1, hal. 51-58, 2017.

[3] L. Dedy Setiawan, "Analisis Dan Perancangan Sistem Informasi Rekam Medik Berbasis Web Pada Puskesmas PAL. V Jambi," J. ManajemanTerapan dan Keuang., vol. 7, no. 2, hal. 181-193, 2018.

[4] J. Sundari, "Sistem Informasi Pelayanan Puskesmas Berbasis Web," Indones. J. Softw. Eng. Sist., vol. 2, no. 1, hal. 44-49, 2016.

[5] A. Kadir, Pengenalan Sistem Informasi. Yogyakarta: Andi Offset, 2014.

[6] S. A. Antara, Dimas Bima, "Perancangan Aplikasi E-Tourism Laguna Teluk Kilauan Sebagai Media Promosi Wisata Berbasis Android," JTKSI, vol. 01, no. 01, hal. 22-25, 2018.

[7] Oktafianto. Muhammad Muslihudin, Analisis Dan Perancangan Sistem Informasi Menggunakan
Model Terstruktur Dan UML. Yogyakarta: Andi Offset, 2016.

[8] T. Sutabri, Konsep Dasar Sistem Informasi. Yogyakarta: Andi Offset, 2012.

[9] D. Permatasari, "Perancangan sistem informasi layanan kesehatan puskesmas ngemplak kabupaten boyolali," UM Surakarta, 2014.

[10] S. K. S. Ratna Indah Dwipunti, "Perancangan Sistem Informasi Administrasi Keuangan Pada Sanggar Tari Sekar Tanjung Kendal Berbasis Client Server," KOMPAK, vol. 8, no. 1, hal. 20-24, 2015.

[11] T. Saleh, "Sistem Informasi Administrasi Keuangan MA Ibrahimy Secang Kalipuro Banyuwang," AiTech, vol. 3, no. 1, hal. 51-58, 2017.

[12] X. Jing, "Multimedia Teaching Platform Design for Urban Planning Course Based on Information Entropy Research progress," iJET, vol. 12, no. 7, hal. 4-16, 2017.

[13] Y. Yudhanto dan P. Alfianto, "Aplikasi Android 'Cari Dokter' Untuk Wilayah Surakarta," SEMNASTEKNOMEDIA, vol. 3, no. 1, hal. 57-62, 2015.

[14] F. Satria, Pemrograman WEB (HTML, CMS dan JavaScript). Yogyakarta: Andi Offset, 2016.

[15] M. M. A. Fauzi, Program Database Visual Basic 6 and SQL Server 2000. Yogyakarta, 2013.

[16] Ernawati, Etty, "Pengembangan Sistem Informasi Rumah Sakit (Simr) Untuk Meningkatkan Kualitas Pelayanan", 2012.

[17] Pressman, Roger S. Rekayasa Perangkat Lunak (Pendekatan Praktisi) Edisi 7 Buku 1. Yogyakarta: Andi, 2012. 